\title{
Modelling Snowmelt Runoff under Climate Change Scenarios in an Ungauged Mountainous Watershed, Northwest China
}

\author{
Yonggang Ma, ${ }^{1,2,3}$ Yue Huang, ${ }^{1} \mathrm{Xi}$ Chen, ${ }^{1}$ Yongping $\mathrm{Li},{ }^{4}$ and Anming Bao ${ }^{1}$ \\ ${ }^{1}$ State Key Laboratory of Desert and Oasis Ecology, Xinjiang Institute of Ecology and Geography, Chinese Academy of Sciences, \\ Urumqi 830011, China \\ ${ }^{2}$ College of Resources and Environment Science, Xinjiang University, Urumqi 830046, China \\ ${ }^{3}$ Xinjiang Remote Sensing Center, Urumqi 830011, China \\ ${ }^{4}$ MOE Key Laboratory of Regional Energy Systems Optimization, Sino-Canada Resources and Environmental Research Academy, \\ North China Electric Power University, Beijing 102206, China \\ Correspondence should be addressed to Yue Huang; hy800821@163.com
}

Received 1 February 2013; Accepted 14 April 2013

Academic Editor: Songlin Nie

Copyright @ 2013 Yonggang Ma et al. This is an open access article distributed under the Creative Commons Attribution License, which permits unrestricted use, distribution, and reproduction in any medium, provided the original work is properly cited.

\begin{abstract}
An integrated modeling system has been developed for analyzing the impact of climate change on snowmelt runoff in Kaidu Watershed, Northwest China. The system couples Hadley Centre Coupled Model version 3 (HadCM3) outputs with Snowmelt Runoff Model (SRM). The SRM was verified against observed discharge for outlet hydrological station of the watershed during the period from April to September in 2001 and generally performed well for Nash-Sutcliffe coefficient (EF) and water balance coefficient (RE). The EF is approximately over 0.8 , and the water balance error is lower than $\pm 10 \%$, indicating reasonable prediction accuracy. The Statistical Downscaling Model (SDSM) was used to downscale coarse outputs of HadCM3, and then the downscaled future climate data were used as inputs of the SRM. Four scenarios were considered for analyzing the climate change impact on snowmelt flow in the Kaidu Watershed. And the results indicated that watershed hydrology would alter under different climate change scenarios. The stream flow in spring is likely to increase with the increased mean temperature; the discharge and peck flow in summer decrease with the decreased precipitation under Scenarios 1 and 2. Moreover, the consideration of the change in cryosphere area would intensify the variability of stream flow under Scenarios 3 and 4 . The modeling results provide useful decision support for water resources management.
\end{abstract}

\section{Introduction}

Northwest of China is a typical arid region, which is characterized by low and irregular rainfall, high temperature, and evaporation. A major proportion of flow in the rivers in this region is contributed by snow and glacier-fed river catchments located in the mountainous area [1]. Particularly in springs, the inflow coming from the snowmelt process is accounting for an average of approximately $70 \%$ of total annual river flow [2]. Snowmelt is the major source of many rivers and significantly contributes to the local populace and social-economic development. However, when snowmelt and storms combine, the area is also easily flooded [3, 4]. Therefore, it is essential to estimate the snowmelt runoff for these mountainous catchments and evaluate the impact of climate change on snowmelt runoff for water resources management of the arid area.

Hydrologic model is a useful tool for flood forecasting and water resources management [5]. Previously, different hydrological models with a snow component were used to simulate the daily stream flows in snow- and glacierfed catchments $[1,6-9]$. However, most of the hydrological models are not satisfactory for daily stream flow simulation and forecasting in the mountainous catchments, where the snowmelt is a major factor in the water cycle [10,11]. Since most of these models are sensitive to the precipitation forcing, the precipitation data available from the high altitude catchments is not of very good quality $[1,12]$. Lack of information for temporal and spatial rainfall variability has brought large uncertainty in snowmelt runoff forecasting $[6,13]$. 
Snowmelt Runoff Model (SRM) [14] is one of the widely used models to simulate and forecast the daily stream flows in these types of mountainous catchments [1]. It is currently based on a simple degree-day method. The daily precipitation, air temperature, and snow cover area are the input data. In addition, a number of basin characteristics such as basin area, zone area, and the hypsometric (area elevation) curve are also needed. The daily water produced from the snowmelt and rainfall is superimposed on the calculated recession flow and transformed into daily discharge from the catchment [1]. The main advantage of the SRM is its weak sensibility to the precipitation inputs and more sensitive to the daily snow cover and temperature data. Due to the progress of satellite remote-sensing of the cryosphere, the SRM has been applied to larger and larger basins [15]. Previously, a number of researchers applied the SRM to simulate the snow melting runoff by using MODIS snow cover products as basic inputs [15-18]. Additionally, few researchers found that the SRM combined with MODIS snow cover and TRMM rainfall data significantly improves regional runoff modeling for the Himalayas [19]. In the Northwest of China, several studies focused on applying the SRM to simulate the snowmelt runoff processes [2022]. Wang et al. [23] used the SRM, in which MODIS snow covered area products and meteorological stations data were used as input parameters, to simulate the snowmelt process in three watersheds in the upper reaches of Heihe River Basin. Zhang et al. [21] used the SRM for daily runoff forecast of Manasi Watershed, in which CMA T213 meteorological data for forecasting zonal temperature and precipitation of the watershed were used in snow melting runoff modeling. Zhang et al. [3] analyzed the influence of catchment characteristics on the parameters of the SRM and discussed the corresponding determination strategy to improve the accuracy of snowmelt simulation and forecast. Ma and Cheng [22] found a Nash-Sutcliffe coefficient value of 0.80 when simulating the stream flow in the Gongnaisi Watershed in the Western Tianshan Mountains by applying the SRM. The previous studies of applying the SRM to mountainous watershed of Northwest China and other regions of the world suggest that the model can efficiently be applied in the snow- and glacier-fed river basins to simulate and forecast the daily stream flows.

Most recently, the SRM has been applied to evaluate the effect of climate change on seasonal snow cover and runoff [10]. For example, Tahir et al. [1] integrated the SRM with MODIS remote-sensing snow cover products to simulate the daily runoff and to study the climate change impact on discharge in the Hunza River Basin. Immerzeel et al. [16] applied the SRM in the upper Indus Basin and reported that regional warming is affecting the hydrology process due to accelerated glacial melting during the simulation period. Liu et al. [24] simulated the relationship among air temperature, precipitation, and runoff when the temperature rises by $1^{\circ} \mathrm{C}$ in Dongkemadi River Basin, China; the result indicated that the rise of air temperature would speed up snowmelt, and the changes of precipitation state are the main reasons of the runoff increase from May to June; the rise of runoff from July to October is mainly caused by the melting of glacier.

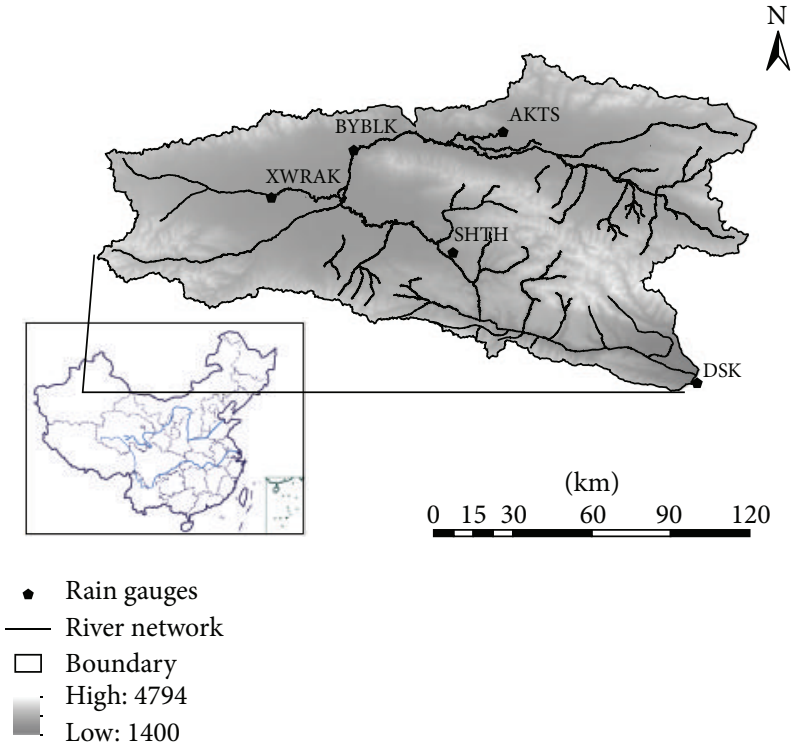

FIGURE 1: Study area of Kaidu Watershed (China's borders were downloaded from National Administration of Surveying, Mapping, and Geoinformation; number: GS(2008)1045).

However, the scenarios of future climate change in most pervious SRM simulations were simply defined by increasing or decreasing the temperature and precipitation forcing data. Few works focus on integrating climate change scenarios which based on the General Circulation Model (GCM) with the SRM in the snowmelt runoff modeling of mountainous catchment [25].

Therefore, the objective of this study is to develop an intergraded modeling system through coupling the GCM outputs with the SRM for analyzing the impact of future climate change on snowmelt flow and water resources in the Kaidu Watershed, Northwest China. In the study, the SRM model will be used to simulate the hydrological response on snow and glacier melting runoff; GCM data will be used for defining future climate change scenarios, used as inputs for simulating the climate impact on hydrology. The results obtained will be used for helping the planers to establish effective water exploitation and allocation policies and thus improve the local ecosystem sustainability and social-economic development.

\section{Study Area}

The Kaidu Watershed is located in the middle reach of the Tarim River and has an area of approximately $19.0 \times 10^{3} \mathrm{~km}^{2}$. Figure 1 shows the outline of the catchment with the major river system, rain gauges, and DEM. There is no doubt that the discharge and flood events of Kaidu River not only represent destructive natural hazard in the mountainous, but also are the obvious complements for the lower reach of the Tarim River. The mean elevation of the watershed ranges from $2400 \mathrm{~m}$ to $2600 \mathrm{~m}$ above sea level in the basin, and from $4000 \mathrm{~m}$ to $5500 \mathrm{~m}$ in the mountain. The spatial and temporal distribution of precipitation is strongly heterogeneous. The 
average rainfall is about $273 \mathrm{~mm} /$ year. More than $80 \%$ of the total annual precipitation falls from May to September, and less than $20 \%$ of the total falls from November to the following April. The Kaidu Watershed has an extreme cold climate with an average temperature of $-4.16^{\circ} \mathrm{C}$. Average pan evaporation is about $1157 \mathrm{~mm} /$ year. Snow melting is one of the most important sources in spring and summer.

There are two possible water release peaks per year. The snow on the lower mountains melts in spring, and glaciers in the high mountains melt in summer. Stream flow from May to October contributes more than $70 \%$ of the total flow. Peak flows at the DSK station reach around $400-700 \mathrm{~m}^{3} / \mathrm{s}$ in August and September and drop to almost zero during the end of the dry season. The spring snowmelt water is also the main water source for the germination of the Bayanbulak pasture [3]. Therefore, it is deemed necessary to develop effective modeling system for analyzing the impact of climate change on snowmelt runoff and water resources in the study area $[13,26]$.

\section{Methodology}

3.1. Data Collection. Kaidu Watershed is a typical ungauged catchment in Northwest China, and conventional meteorological observations began in 1956. There are six gauge stations in the watershed, but only two stations have continuous long time records of the meteorological and hydrological elements. One is the Bayanbulak (BYBLK) station which records temperature and precipitation data, and the other is the Dashankou (DSK) station which provides temperature and runoff data (Figure 1). General meteorological data comprising air temperatures and daily precipitation were collected for the period of 1961-2001.

The input topography map was derived from the $90 \mathrm{~m}$ $\times 90 \mathrm{~m}$ digital elevation model (DEM). As the physical environment varies drastically with increasing altitudes, the basin with a great elevation range was divided into several zones to better describe the physical environment [1]. Former studies suggest that an interval less than $500 \mathrm{~m}$ is better for the elevation zones, while excessively small intervals would increase the modeling complexity. Thus, we divided the elevation zone with an interval of $425 \mathrm{~m}$ in this study (Figure 2).

The Moderate Resolution Imaging Spectroradiometer (MODIS) MOD10A2 products were used to generate snow cover inputs of the SRM. The MODIS/Terra Snow Cover 8Day L3 Global $500 \mathrm{~m}$ Grid (MOD10A2) contains data fields for maximum snow cover extent over an 8-day repeated period and has a resolution of approximately $500 \mathrm{~m}$ completely covering the Kaidu Watershed [27]. When the percentage of cloud cover exceeded $20 \%$ on a specific date, the record was removed and then the average snow cover was estimated on this date by interpolating linearly between the previous and the next available cloud-free images [28]. The snow cover area was also calculated for the different altitudinal zones to use further for snowmelt-runoff modeling.

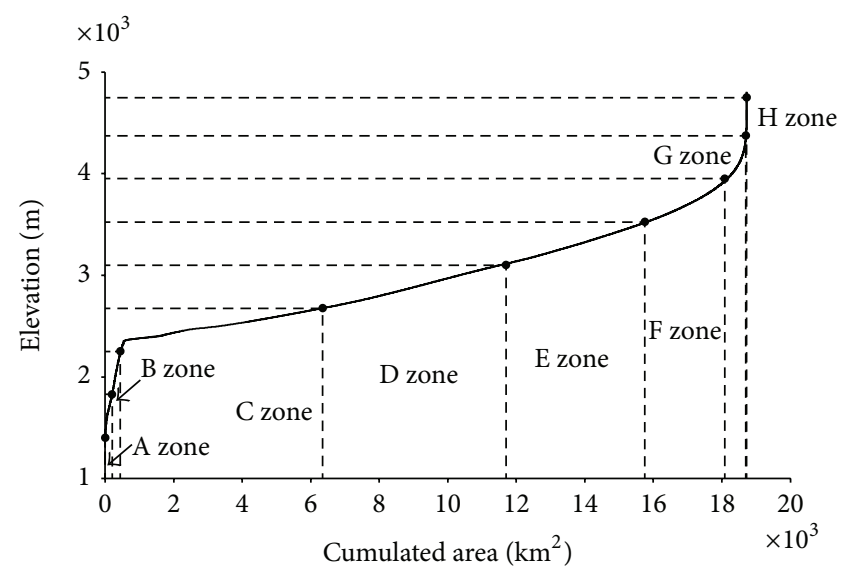

FIGURE 2: Area distributions of different elevation zones in the Kaidu Watershed.

3.2. Snowmelt-Runoff Model (SRM). SRM is a conceptual, deterministic, degree day hydrologic model used to simulate daily runoff resulting from snowmelt and rainfall in mountainous regions. SRM requires daily temperature, precipitation, and daily snow covered area values as input parameters. Stream flow is calculated according to the following equation [14]:

$$
\begin{aligned}
Q_{n+1}= & {\left[\operatorname{Csn} \cdot a_{n}\left(T_{n}+\Delta T_{n}\right) S_{n}+\operatorname{Crn} P_{n}\right] \cdot A } \\
& \cdot\left(\frac{10000}{86400}\right) \cdot\left(1-k_{n+1}\right)+Q_{n} \cdot k_{n+1},
\end{aligned}
$$

where $Q_{n+1}\left(\mathrm{~m}^{3} / \mathrm{s}\right)$ is the discharge at day $n+1$; Csn $(-)$ is the snow runoff coefficient; $a_{n}$ is degree day factor on day $n$ $\left(\mathrm{cm}^{\circ} \mathrm{C}^{-1} \mathrm{~d}^{-1}\right) ; T_{n}+\Delta T_{n}\left({ }^{\circ} \mathrm{C}\right)$ are the degree days; $S_{n}(-)$ is the fractional snow cover; $\mathrm{Crn}(-)$ is the rainfall runoff factor; $P_{n}(\mathrm{~cm})$ is the rain on day $n ; A$ is total area $\left(\mathrm{km}^{2}\right) ; k_{n+1}$ is the discharge recession coefficient.

The SRM was used to simulate the daily discharges in the Kaidu River at outlet DSK station. It used the MODIS snow cover data as basic input. The model was run for snowmelt season in 2001 (April to September 2001) to simulate the daily discharges in the Kaidu Watershed. The SRM parametric values were estimated during the calibration of the model and extracted from the studies conducted previously on mountainous watersheds in Tianshan Mountains (e.g., [3, 22]).

The time series of discharge at DSK station available for 2001 was used for calibrating the SRM. The Nash-Sutcliffe coefficient (EF) and the water balance coefficient (RE) were used to evaluate the relationship between the observed and simulated daily discharges in the applications of the SRM. Consider

Nash-Sutcliffe coefficient: $\mathrm{EF}=1-\frac{\sum_{i=1}^{n}\left(Q_{\mathrm{obs}, i}-Q_{\mathrm{sim}, i}\right)^{2}}{\sum_{i=1}^{n}\left(Q_{\mathrm{obs}, i}-\bar{Q}_{\mathrm{obs}}\right)^{2}}$,

Water balance coefficient: $\mathrm{RE}=1-\frac{\sum_{i=1}^{n}\left|Q_{\mathrm{obs}, i}-Q_{\mathrm{sim}, i}\right|}{\sum_{i=1}^{n} Q_{\mathrm{obs}, i}}$, 
where $Q_{\mathrm{obs}, i}$ is the observed discharge at time step $i, Q_{\mathrm{sim}, i}$ is the simulated discharge at time step $i, \bar{Q}_{\mathrm{obs}}$ is the mean observed discharge, and $n$ is the total number of time steps. Note that the SRM estimations are optimal when EF and RE are close to 1.

3.3. Climate Change Impact Detection. Globe circulation model (GCM) accounts for dynamics of global circulation patterns and earth surface-atmosphere system, but their results are too coarse to be used for hydrologic processes [25]. In order to link output from GCM with basin-scale hydrologic models, a downscaling process is necessary. The Statistical Downscaling Model (SDSM) [29] was used to downscale the GCM outputs for the Kaidu Watershed. Daily precipitations as well as daily mean temperature data were chosen as predictand variables for the downscaling experiments.

The Bayanbulak (BYBLK) meteorological stations, which are inside this watershed, and with 50 years of precipitation and temperature records representing the current climate (1961-2000), were identified for the downscaling experiments. Observed daily data of large-scale predictor variables representing the current climate condition was derived from the NCEP reanalysis data set. Climate variables corresponding to the future climate change for the study area were extracted from the Hadley Centre Coupled Model version 3 (HadCM3) output under IPCC SRES A2 and B2 scenarios at a grid point which is closest to the BYBLK station. Data was extracted for three distinct periods named 2020s (covering a 30-year period between 2010 and 2039), 2050s (2040-2069), and 2080s (2070-2099).

The verified SRM would be used to simulate the impact of climate change on the Kaidu River runoff. The verified SRM would be used to simulate the impact of climate change on the Kaidu River runoff. Some researches indicate that the climate change had a significant impact on the hydrological process of the Kaidu Watershed during the past 50 years [3]. In mountainous region like the Kaidu Watershed, variation of river runoff is mainly influenced by two factors: (1) time and space distribution change of the precipitation, and (2) snow and glacier melting which is caused by rising temperatures $[4,6,13]$. Therefore, we defined the future climate change scenarios by using downscaled GCMs simulation data, and also considered the impact of rainfall, snow melting, and glacier melting on stream flows. Four scenarios were defined as follows.

(a) In Scenario 1, the change of cryosphere area was not considered, while the mean temperature and precipitation were changed based on the statistical downscaling results of HadCM3 outputs under SERS A2 scenario.

(b) In Scenario 2, the change of cryosphere area was not considered, while the mean temperature and precipitation area changed based on the statistical downscaling results of HadCM3 outputs under SERS B2 scenario.

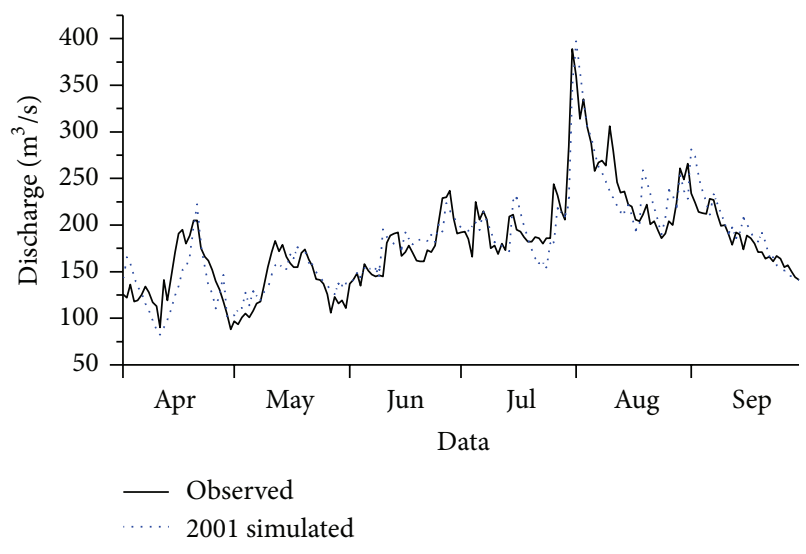

FIGURE 3: Simulation results of the SRM at DSK station in Kaidu Watershed.

(c) In Scenario 3, the mean temperature and precipitation were changed based on the statistical downscaling results of HadCM3 outputs under SERS A2 scenario; in addition, the cryosphere area was assumed to increase or decrease $20 \%$.

(d) In Scenario 4, the mean temperature and precipitation were changed based on the statistical downscaling results of HadCM3 outputs under SERS B2 scenario; the cryosphere area was assumed to increase or decrease $50 \%$.

\section{Results Analysis}

4.1. Results of SRM Simulation. Simulations were performed for the Kaidu Watershed, where the conventional meteorological data were available for the period of 2001. Parameters adjustment was carried out manually by using a trialand-error procedure. Sensitivity analysis was conducted to investigate the effects of the model responses to its parameters and to identify those which should have further calibration [30]. The most sensitive parameters are snowmelt runoff coefficient $\left(C_{s}\right)$, rainfall runoff coefficient $\left(C_{r}\right)$, and degreeday factor $(a)$. The values of the main parameters for SRM in the Kaidu Watershed are listed in Table 1.

Figure 3 shows the simulated and observed hydrographs for snow melting periods. There is a statistically significant relationship between the simulated and the observed data, and the simulated river flow captures the interannual variations well. The simulation results are encouraging with $\mathrm{EF}$ of 0.81 and $\mathrm{RE}$ of 0.91 , respectively. Table 2 presents the statistics for model performance of the SRM during April to September in 2001. The best performance of the model is found in May, and the worst performance of the model is found in April with the lowest EF value of 0.32, and the lowest $R E$ value of 0.84 . In addition, several main parameters in the SRM model can be inputted by basin wide (BWM) or by zone (ZWM); simulation results of the stream flow under a different parameter input mode were also compared (Figure 4). 
TABLE 1: Value of main parameters for the SRM.

\begin{tabular}{|c|c|c|c|c|c|c|c|c|}
\hline Parameter & A zone & B zone & C zone & D zone & E zone & F zone & G zone & H zone \\
\hline $\begin{array}{l}\text { Lapse rate } \\
\left({ }^{\circ} \mathrm{C} / 100 \mathrm{~m}\right)\end{array}$ & 0.55 & 0.55 & 0.55 & 0.55 & 0.65 & 0.65 & 0.65 & 0.65 \\
\hline$T_{\text {cric }}\left({ }^{\circ} \mathrm{C}\right)$ & \multicolumn{6}{|c|}{$\begin{array}{l}-0.5 \text { (Apr, Sep) } \\
0 \text { (May-Aug) }\end{array}$} & -0.5 & -0.5 \\
\hline $\begin{array}{l}\mathrm{DDF} \\
\left(\mathrm{cm}^{\circ} \mathrm{C}^{-1} \mathrm{~d}^{-1}\right)\end{array}$ & \multicolumn{6}{|c|}{$\begin{array}{l}0.3 \text { (Apr, Sep) } \\
0.45 \text { (May-Jul) } \\
0.55 \text { (Aug) }\end{array}$} & \multicolumn{2}{|c|}{0.6} \\
\hline Lag time $(\mathrm{h})$ & \multicolumn{8}{|c|}{18} \\
\hline$C_{s}$ & 0 & 0 & 0.1 & 0.1 & 0.15 & 0.15 & 0.2 & 0.2 \\
\hline \multirow{3}{*}{$C_{r}$} & 0.35 (Apr, Sep) & 0.30 (Apr, Sep) & 0.30 (Apr, Sep) & 0.30 (Apr, Sep) & 0.25 (Apr, Sep) & 0.25 (Apr, Sep) & 0.25 & 0.25 \\
\hline & 0.40 (May-Jul) & 0.35 (May-Jul) & 0.35 (May-Jul) & 0.35 (May-Aug) & 0.30 (May-Jul) & 0.30 (May-Aug) & & \\
\hline & 0.45 (Aug) & 0.40 (Aug) & 0.40 (Aug) & & 0.35 (Aug) & & & \\
\hline \multirow{2}{*}{ RCA } & \multirow[t]{2}{*}{1} & 1 & \multirow[t]{2}{*}{1} & \multirow[t]{2}{*}{1} & 1 (Apr 1th-15th) & 1 (Apr 1th-15th) & \multirow[t]{2}{*}{0} & \multirow[t]{2}{*}{0} \\
\hline & & & & & 0 (Apr 16th-Sep) & 0 (Apr 15th-Sep) & & \\
\hline$X_{c}$ & & & & 0.98 & & & & \\
\hline$Y_{c}$ & & & & 0.02 & & & & \\
\hline
\end{tabular}

TABLE 2: Performance of the daily snowmelt runoff simulation.

\begin{tabular}{lcc}
\hline & EF & RE \\
\hline Snowmelt seasons & 0.81 & 0.91 \\
April & 0.32 & 0.84 \\
May & 0.69 & 0.91 \\
June & 0.66 & 0.93 \\
July & 0.66 & 0.91 \\
August & 0.63 & 0.92 \\
September & 0.48 & 0.93 \\
\hline
\end{tabular}

4.2. Downscaling Results of HadCM3 Outputs. Observed daily data of large-scale predictor variables representing the current climate condition (1961-2000) which are derived from the NCEP reanalysis data set were used to investigate the percentage of variance explained by each predictandpredictor pairs. The correlation between the predictor variables and each predictand is very low in case of daily precipitation compared to that of daily mean temperature. Moreover, the strength of individual predictors varies on a month by month basis. Therefore, the most appropriate combination of predictors has to be chosen by looking at the analysis output of all the twelve months. From the 40 years of data representing the current climate, the first 30 years (1961-1990) were considered for calibrating the regression models, while the remaining ten years of the data (1991-2000) were used to validate those models. Some of the SDSM setup parameters, such as event threshold, bias correction, and variance inflation, were adjusted during calibration to get the best statistical agreement between observed and simulated climate variables. Figure 5(a) shows the performance of the SDSM during the validation periods. The graphs show a comparison between the observed and simulated outputs for the cases of mean precipitation. Figure 5(b) illustrates the validation performance of the downscaling model for mean

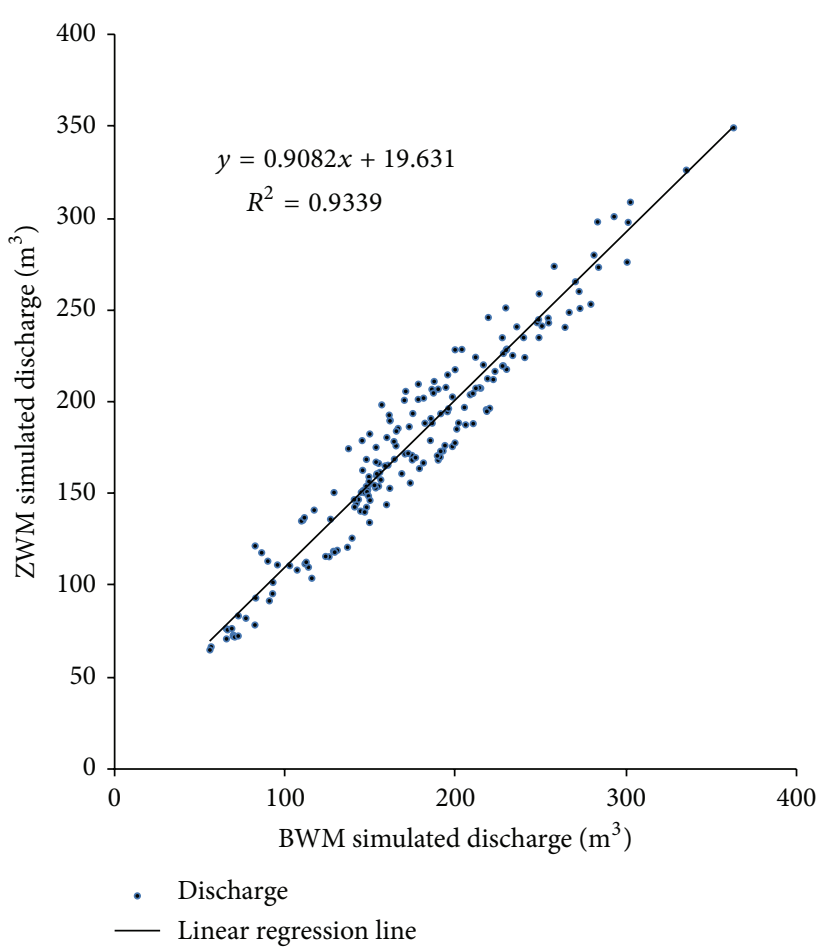

FIGURE 4: Comparation of the simulated discharges used parameter values by basin wide (BWM) and by zones (ZWM).

temperature, and the result shows satisfactory agreement between the observed data and the simulation outputs.

Figure 6(a) displays the average changes in precipitation under the A2 and B2 scenarios in 2020s to 2080s, and Figure 6(b) shows changes in mean temperature. The results indicate that the annual precipitation of the watershed in the future would exhibit a decreasing trend. Both A2 and B2 scenarios show a decreasing trend in monthly precipitation 


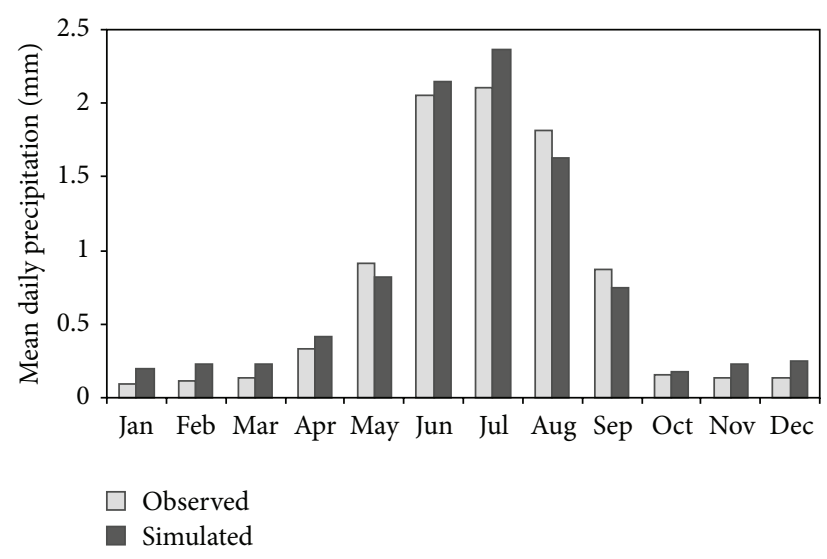

(a)

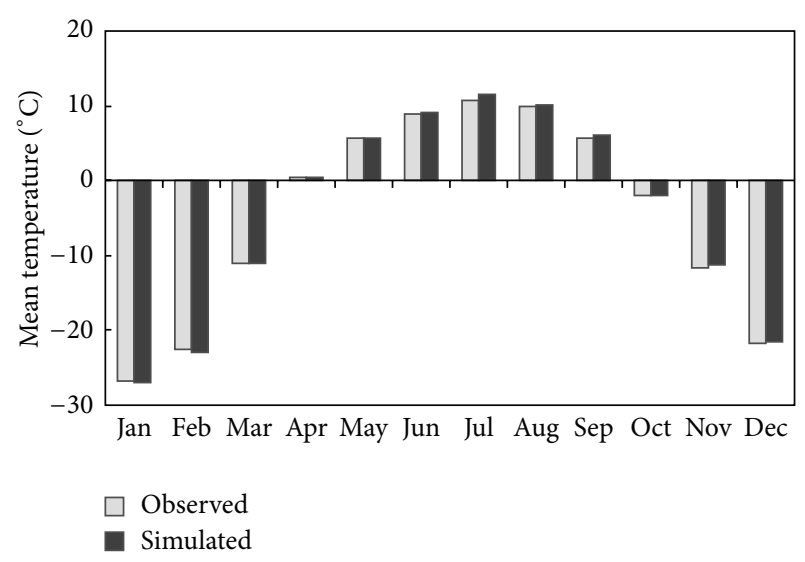

(b)

FIGURE 5: Validation results of SDSM downscaling of daily precipitation and daily mean temperature at BYBLK.

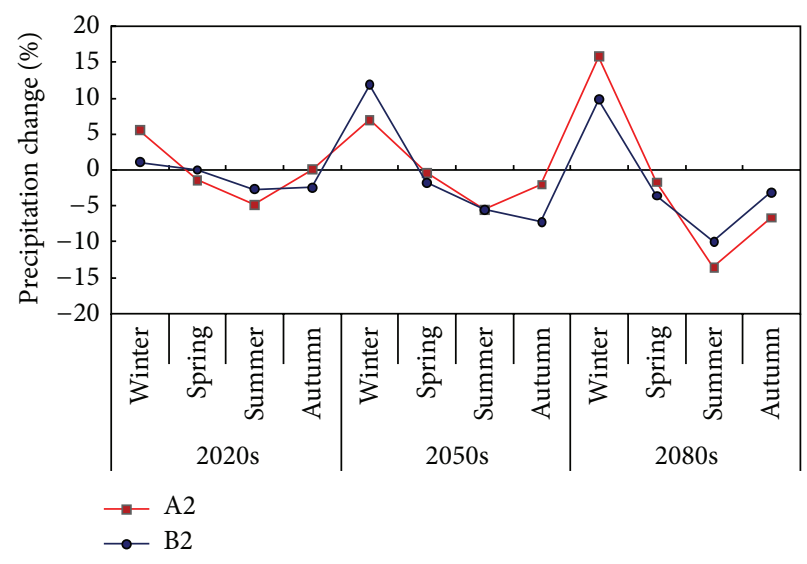

(a)

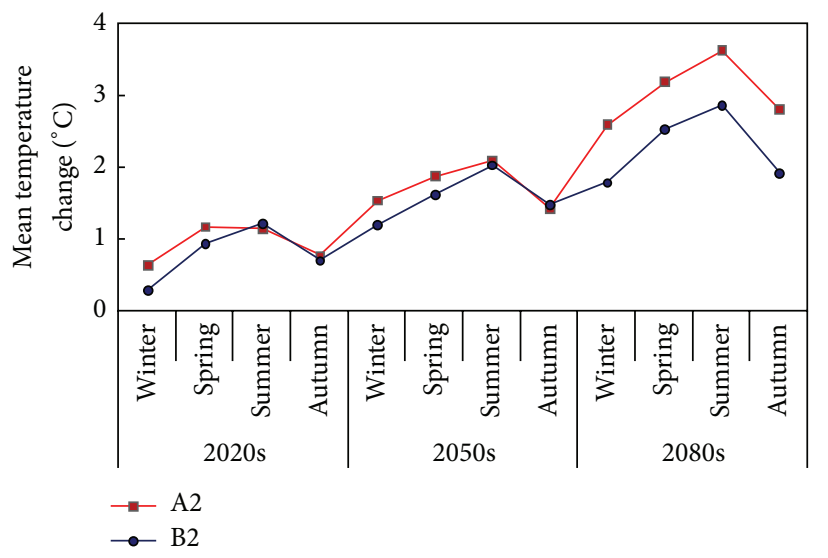

(b)

FIGURE 6: Changes in precipitation and temperature under IPCC SERS A2 and B2 scenarios from 2020s to 2080s.

during spring, summer, and autumn and show an increasing trend in winter. Contrarily, there is an obvious increasing trend for the future mean temperature, at a daily, monthly, seasonal, and yearly scale, respectively. The increase range under A2 scenario is larger than that in B2 scenario in the Kaidu Watershed.

4.3. Impact of Future Climate Change on Snowmelt Runoff. After verification on the present time (year of reference 2001), the SRM was used to study the impact of climate change on the Kaidu River runoff. The simulated discharge in 2001 was used as reference for the present climate. Four scenarios were considered in this study. Figure 7 shows the discharges simulated under Scenario 1 from 2020s to 2080s. In 2020 s, the average precipitation was assumed to decrease $1.4 \%$ and $4.9 \%$ in spring and summer, respectively, while the mean temperatures of the watershed were assumed to increase $1.2^{\circ} \mathrm{C}$ in both spring and summer. In 2050s, the average precipitation was assumed to decrease $0.4 \%$ and $5.6 \%$ in spring and summer, respectively, while the mean temperatures of the catchment were assumed to increase $1.9^{\circ} \mathrm{C}$ and $2.1^{\circ} \mathrm{C}$ in spring and summer, respectively. And in 2080 s, the average precipitation was assumed to decrease $1.8 \%$ and $13.6 \%$ in spring and summer, respectively, while the mean temperatures of the catchment were assumed to increase $3.2^{\circ} \mathrm{C}$ and $3.6^{\circ} \mathrm{C}$ in spring and summer, respectively. The results indicate that the stream flow in spring is likely to increase with the increased mean temperature; the stream flow in summer decreases with the decreased precipitation. The mean discharge during the snow melting seasons is decreased $5.9 \%$ in 2020 s, while increased $1.0 \%$ and $11.8 \%$ in 2050 s and 2080s, respectively. The spring peck flows under Scenario 1 are increased $16.5 \%, 21.1 \%$, and $46.0 \%$ in 2020 s, 2050 s, and 2080s, respectively, while the summer peck flows are decreased $11.9 \%, 6.9 \%$, and $0.5 \%$ in 2020 s, 2050s, and 2080s, respectively.

Figure 8 shows the discharges simulated under Scenario 2 from 2020 s to 2080 s. In 2020 s, the average precipitation was assumed to decrease $0.1 \%$ and $2.7 \%$ in spring and summer, respectively, while the mean temperatures of the catchment were assumed to increase $0.95^{\circ} \mathrm{C}$ and $1.23^{\circ} \mathrm{C}$ in spring and summer, respectively. In 2050 s, the average precipitation was assumed to decrease $1.8 \%$ and $5.6 \%$ in spring and summer, 


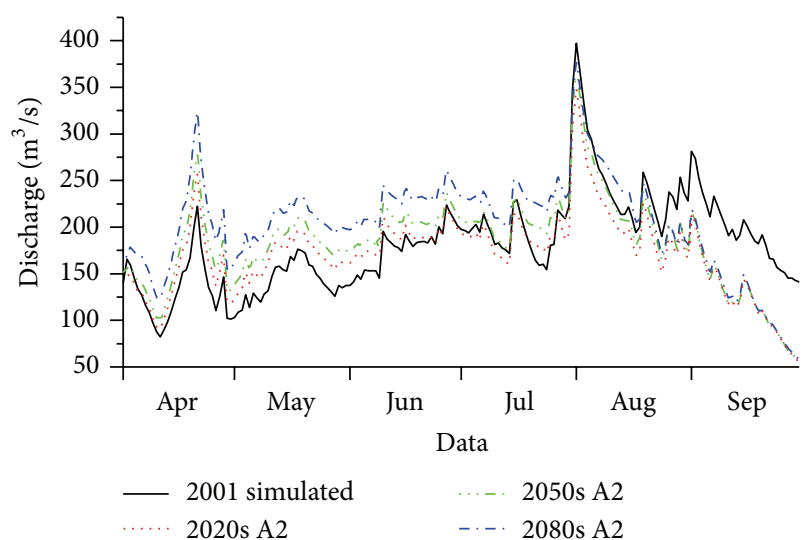

FIGURE 7: Simulated stream flows under Scenario 1 from 2020s to 2080s.

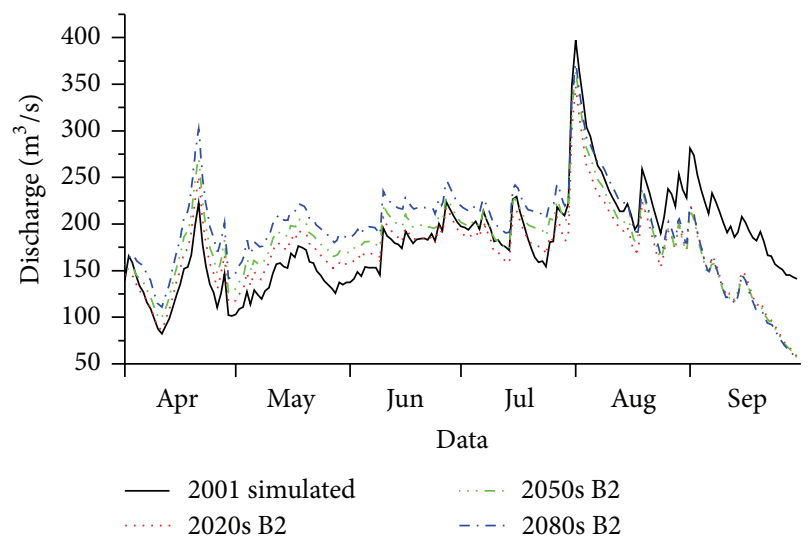

FIGURE 8: Simulated stream flows under Scenario 2 from 2020s to 2080.

respectively, while the mean temperatures of the catchment were assumed to increase $1.6^{\circ} \mathrm{C}$ and $2.0^{\circ} \mathrm{C}$ in spring and summer, respectively. And in 2080 s, the average precipitation was assumed to decrease $3.6 \%$ and $9.9 \%$ in spring and summer, respectively, while the mean temperatures of the catchment were assumed to increase $2.6^{\circ} \mathrm{C}$ and $2.9^{\circ} \mathrm{C}$ in spring and summer, respectively. The results indicate that the variability of the simulated stream flow under Scenario 2 becomes less significant than Scenario 1. The mean discharge is decreased $6.8 \%$ and $1.2 \%$ in 2020 s and 2050 s, respectively; in 2080 s, the mean discharge is increased $6.2 \%$. The spring peck flows under Scenario 2 are increased 13.3\%, 22.9\%, and $36.4 \%$ in 2020 s, 2050 s, and 2080 s, respectively, while the summer peck flows are decreased $12.4 \%, 8.1 \%$, and $6.0 \%$ in 2020s, 2050s, and 2080s, respectively.

Figure 9 shows the discharges simulated under Scenario 3 in 2050s. The snow cover area was assumed to increase $20 \%$ as a result of increasing precipitation in winter; impact of a $20 \%$ decrease in snow cover area of watershed on the Kaidu River discharge was also studied. The results indicate that the spring and summer stream flow is likely to increase with increased snow cover area. A $20 \%$ snow cover increase forces the mean discharge during the snowmelt seasons to increase by $13.7 \%$

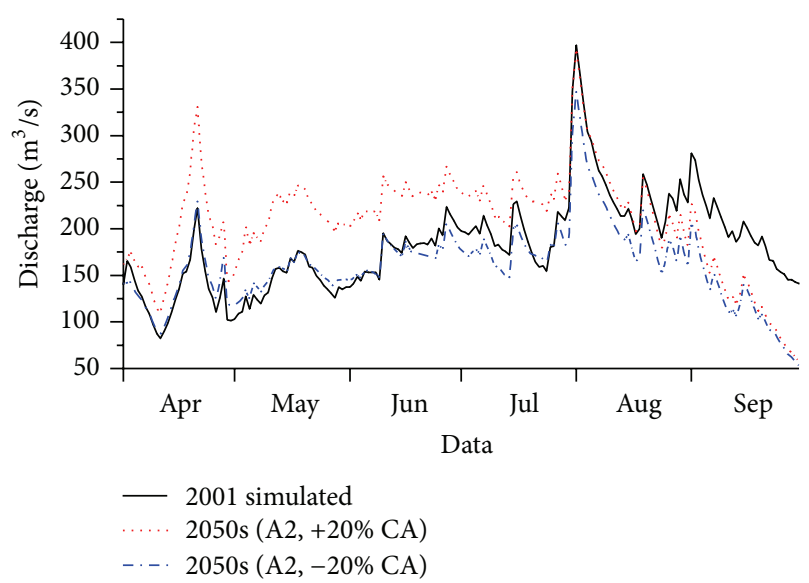

FIGURE 9: Simulated stream flows under Scenario 3 in 2050s.

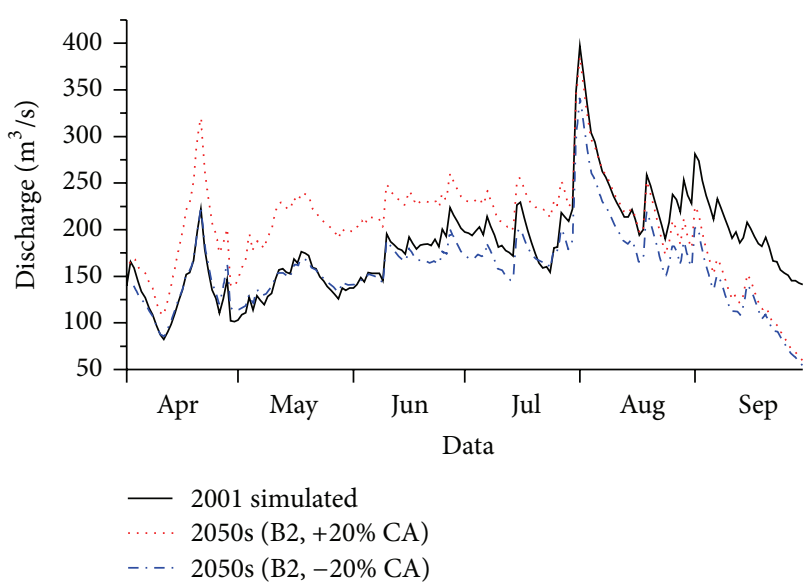

FIGURE 10: Simulated stream flows under Scenario 4 in 2050s.

(i.e., $24.9 \mathrm{~m}^{3} / \mathrm{s}$ ). The mean discharge decreases by $11.6 \%$ if the snow cover area is assumed to decrease by $20 \%$. The increase of snow cover area also results in an obvious increase of peck flow in spring, while the decrease of snow cover area would lead to a decreased peck flow in summer.

Figure 10 shows the discharges simulated under Scenario 4 in 2050s. The snow cover area was assumed to increase 50\% or decrease $50 \%$ in the Kaidu Watershed. The results indicate that the change of simulated stream flow would intensify with increased or decreased $50 \%$ of snow cover area. A 50\% snow cover increase results in a nearly $32.4 \%$ (i.e., $58.8 \mathrm{~m}^{3} / \mathrm{s}$ ) increase in mean discharge, and a $50 \%$ snow cover decrease would result in a $31.8 \%$ (i.e., $57.1 \mathrm{~m}^{3} / \mathrm{s}$ ) decrease in mean discharge during the snowmelt seasons.

\section{Conclusions}

In this study, an integrated modeling system has been developed for estimating the impact of climate change on snowmelt runoff in Kaidu Watershed, Northwest China. The modeling results obtained will provide useful decision support for water resources management and thus improve 
the local ecosystem sustainability and social-economic development.

The SRM based on a degree day factor can efficiently simulate the daily discharge in the snow- and glacier-fed catchments of the Upper Tarim River Basin. The SRM's efficiency in mountainous catchments can be attributed to the use of the MOD10A2 remotely sensed snow cover data as input to the model. The simulated discharge is encouraging with EF value of 0.81 . The HadCM3 outputs of present climate and future SRES A2 and B2 climate scenarios are presented in this paper. And the SDSM was used to bridge the scale gap between coarse GCM outputs and hydrological modeling at the basin scale. In the Kaidu Watershed, temperature shows an increase towards the end of the 21st century, while precipitation presents an increase trend in winter and a decrease trend in other seasons.

By inputting climate data into the SRM, impact of climate change on the hydrological process was estimated. The analysis of the climate change impact indicated that watershed hydrology would alter under different climate change scenarios. The stream flow in spring is likely to increase with the increased mean temperature; the discharge and peck flow in summer decrease with the decreased precipitation under Scenarios 1 and 2. And consideration of the change in cryosphere area would intensify the variability of stream flow. The increased snow cover area also results in the increasing of total flow and peck flow during spring and summer, while the mean discharge and peck flow would decrease if the snow cover area was assumed to decrease under Scenarios 3 and 4. The results of this research provide useful information to manage water resources for the region's future needs.

\section{Acknowledgments}

This research was supported by the "Western Light" Dr. Program of Chinese Academy of Science (XBBS201010); National Program of Key Basic Research Project (no. 2009CB825105); National Natural Science Foundation for Distinguished Young Scholar (51225904).

\section{References}

[1] A. A. Tahir, P. Chevallier, Y. Arnaud, and B. Ahmad, "Snow cover dynamics and hydrological regime of the Hunza River basin, Karakoram Range, Northern Pakistan," Hydrology and Earth System Sciences, vol. 15, no. 7, pp. 2275-2290, 2011.

[2] J. Wang, Y. P. Shen, A. X. Lu et al., "Impact of climate change on snowmelt runoff in the mountainous regions of northwest China," Journal of Glaciology and Geocryology, vol. 23, no. 1, pp. 28-33, 2001.

[3] Y. C. Zhang, B. L. Li, A. M. Bao, C. H. Zhou, X. Chen, and X. R. Zhang, "Study on snowmelt runoff simulation in the Kaidu River basin," Science in China, Series D, vol. 50, no. 1, pp. 26-35, 2007.

[4] Y. Huang, X. Chen, Y. P. Li, A. M. Bao, and Y. G. Ma, "A simulation-based two-stage interval-stochastic programming model for water resources management in Kaidu-Konqi watershed, China," Journal of Arid Land, vol. 4, no. 4, pp. 390-398, 2012.
[5] G. B. Sahoo, C. Ray, and E. H. de Carlo, "Calibration and validation of a physically distributed hydrological model, MIKE SHE, to predict streamflow at high frequency in a flashy mountainous Hawaii stream," Journal of Hydrology, vol. 327, no. 1-2, pp. 94-109, 2006.

[6] Y. Huang, X. Chen, Y. Li, P. Willems, and T. Liu, "Integrated modeling system for water resources management of Tarim River Basin," Environmental Engineering Science, vol. 27, no. 3, pp. 255-269, 2010.

[7] A. A. Şorman, A. Şensoy, A. E. Tekeli, A. Ü. Şorman, and Z. Akyürek, "Modelling and forecasting snowmelt runoff process using the HBV model in the eastern part of Turkey," Hydrological Processes, vol. 23, no. 7, pp. 1031-1040, 2009.

[8] A. Verdhen and T. Prasad, "Snowmelt Runoff simulation models and their suitability in Himalayan conditions," in Snow and Glacier Hydrology, IAHS Publication no. 218, Kathmandu, Nepal, 2001.

[9] WMO, Intercomparison of Models of Snowmelt Runoff, World Meteorological Organization, Geneva, Switzerland, 1986.

[10] J. Martinec, A. Rango, and R. Roberts, Snowmelt Runoff Model (SRM) User's Manual, 2007.

[11] Z. Liu and S. T. Y. Tong, "Using HSPF to model the hydrologic and water quality impacts of riparian land-use change in a small watershed," Journal of Environmental Informatics, vol. 17, no. 1, pp. 1-14, 2011.

[12] H. Zhao, J. Zhang, R. T. James, and J. Laing, "Application of MIKE SHE/MIKE 11 model to structural BMPs in S191 Basin, Florida," Journal of Environmental Informatics, vol. 19, no. 1, pp. 10-19, 2012.

[13] Y. Huang, X. Chen, Y. P. Li, G. H. Huang, and T. Liu, "A fuzzybased simulation method for modelling hydrological processes under uncertainty," Hydrological Processes, vol. 24, no. 25, pp. 3718-3732, 2010.

[14] J. Martinec, "Snowmelt-Runoff Model for stream flow forecasts," Nordic Hydrology, vol. 6, no. 3, pp. 145-154, 1975.

[15] M. V. Georgievsky, "Application of the Snowmelt Runoff model in the Kuban river basin using MODIS satellite images," Environmental Research Letters, vol. 4, no. 4, Article ID 045017, pp. $1-5,2009$.

[16] W. W. Immerzeel, P. Droogers, S. M. de Jong, and M. F. P. Bierkens, "Large-scale monitoring of snow cover and runoff simulation in Himalayan river basins using remote sensing," Remote Sensing of Environment, vol. 113, no. 1, pp. 40-49, 2009.

[17] S. Lee, A. G. Klein, and T. M. Over, "A comparison of MODIS and NOHRSC snow-cover products for simulating streamflow using the Snowmelt Runoff Model," Hydrological Processes, vol. 19, no. 15, pp. 2951-2972, 2005.

[18] V. H. Prasad and P. S. Roy, "Estimation of snowmelt runoff in Beas Basin, India," Geocarto International, vol. 20, no. 2, pp. 4147, 2005.

[19] B. Bookhagen and D. W. Burbank, "Toward a complete Himalayan hydrological budget: spatiotemporal distribution of snowmelt and rainfall and their impact on river discharge," Journal of Geophysical Research F, vol. 115, no. 3, Article ID F03019, 2010.

[20] T. Liu, P. Willems, X. W. Feng et al., "On the usefulness of remote sensing input data for spatially distributed hydrological modelling: case of the Tarim River basin in China," Hydrological Processes, vol. 26, no. 3, pp. 335-344, 2012.

[21] P. Zhang, J. Wang, and Y. Liu, "Application of SRM to flood forecast and forwarning of Manasi River Basin in Spring," 
Remote Sensing Technology and Application, vol. 24, no. 4, pp. 456-461, 2009.

[22] H. Ma and G. Cheng, "A test of Snowmelt Runoff Model (SRM) for the Gongnaisi River basin in the western Tianshan Mountains, China," Chinese Science Bulletin, vol. 48, no. 20, pp. 2253-2259, 2003.

[23] C. Wang, C. Y. Zhao, and Z. D. Feng, "Simulating snow process by using SRM in different watersheds in the upper reaches of Heihe river basin," Journal of Lanzhou University (Natural Sciences), vol. 47, no. 3, pp. 1-8, 2011.

[24] J. Liu, J. Yang, R. Chen, and Y. Yang, "The simulation of snowmelt runoff model in the Dongkemadi River Basin, headwater of the Yangtze River," Acta Geographica Sinica, vol. 61, no. 11, pp. 1149-1159, 2006.

[25] M. Akhtar, N. Ahmad, and M. J. Booij, "Use of regional climate model simulations as input for hydrological models for the Hindukush-Karakorum-Himalaya region," Hydrology and Earth System Sciences Discussions, vol. 5, pp. 865-902, 2008.

[26] Y. P. Li and G. H. Huang, "Planning agricultural water resources system associated with fuzzy and random features," Journal of the American Water Resources Association, vol. 47, no. 4, pp. 841860, 2011.

[27] D. Hall, G. Riggs, and V. Salomonson, Updated Weekly MODIS/Terra Snow Cover 8-Day L3 Global 500 M Grid V005, [March 2000 to December 2009], National Snow and Ice Data Center. Digital Media, Boulder, Colo, USA, 2006.

[28] Q. K. Hassan, N. S. Sekhon, R. Magai, and P. McEachern, "Reconstruction of snow water equivalent and snow depth using remote sensing data," Journal of Environmental Informatics, vol. 20, no. 2, pp. 67-74, 2012.

[29] R. L. Wilby, C. W. Dawson, and E. M. Barrow, "SDSM-a decision support tool for the assessment of regional climate change impacts," Environmental Modelling and Software, vol. 17, no. 2, pp. 147-159, 2002.

[30] Y. P. Li and G. H. Huang, "Fuzzy-stochastic-based violation analysis method for planning water resources management systems with uncertain information," Information Sciences, vol. 179, no. 24, pp. 4261-4276, 2009. 


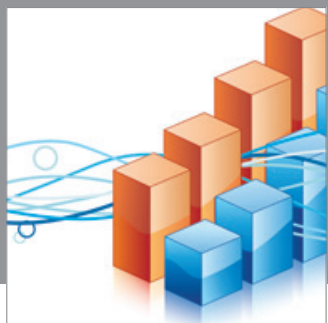

Advances in

Operations Research

mansans

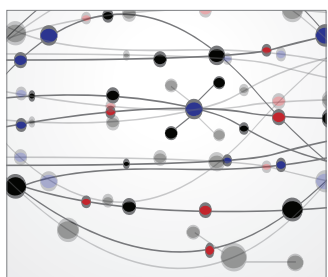

The Scientific World Journal
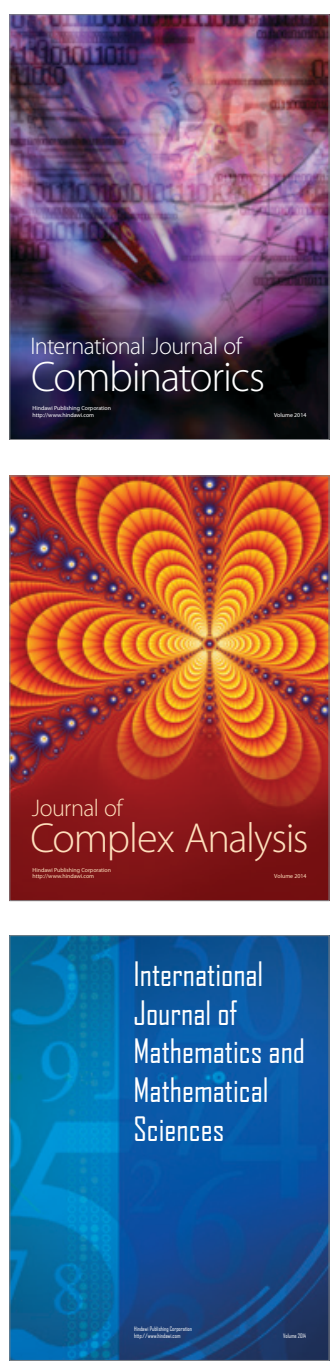
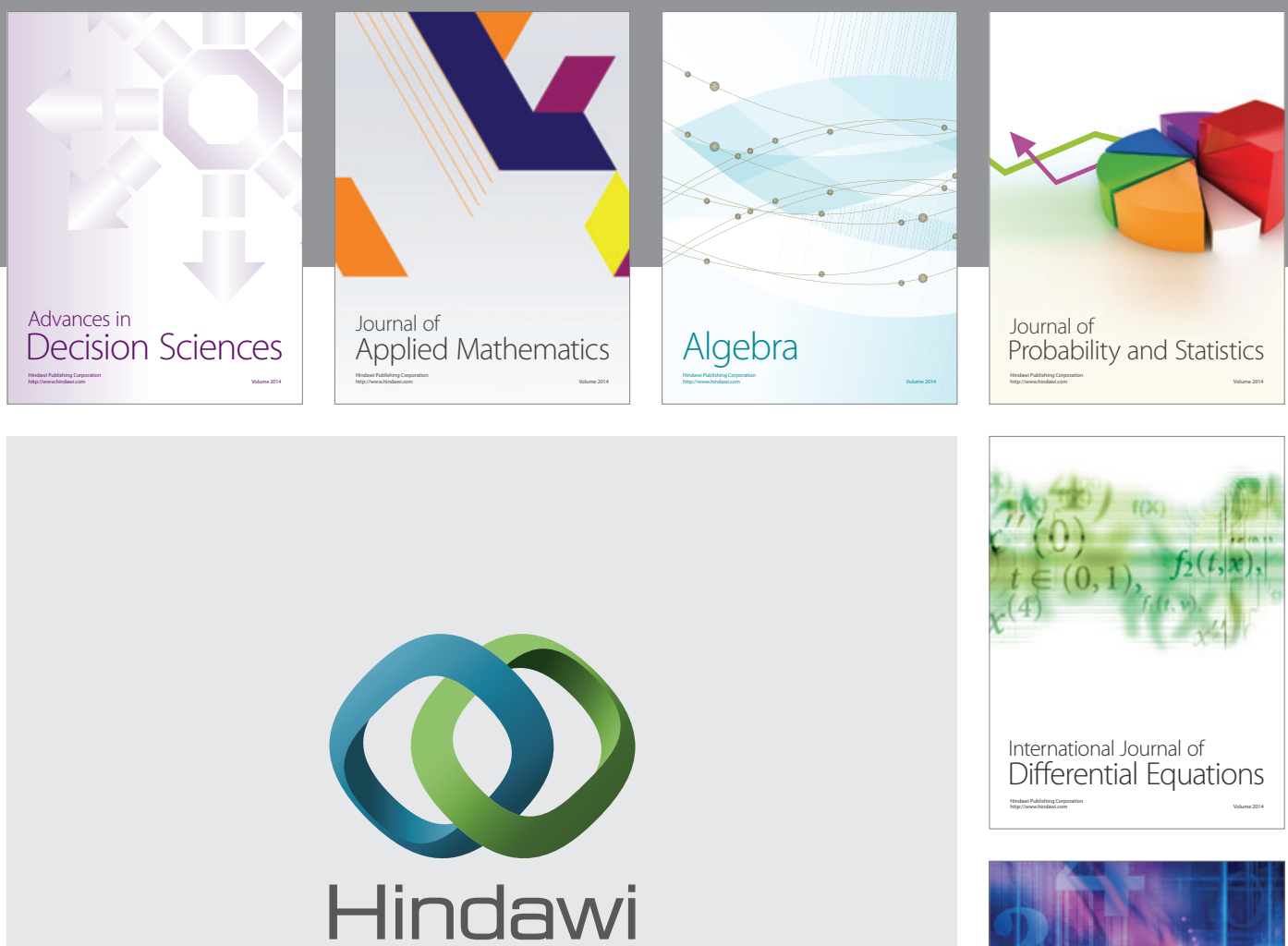

Submit your manuscripts at http://www.hindawi.com
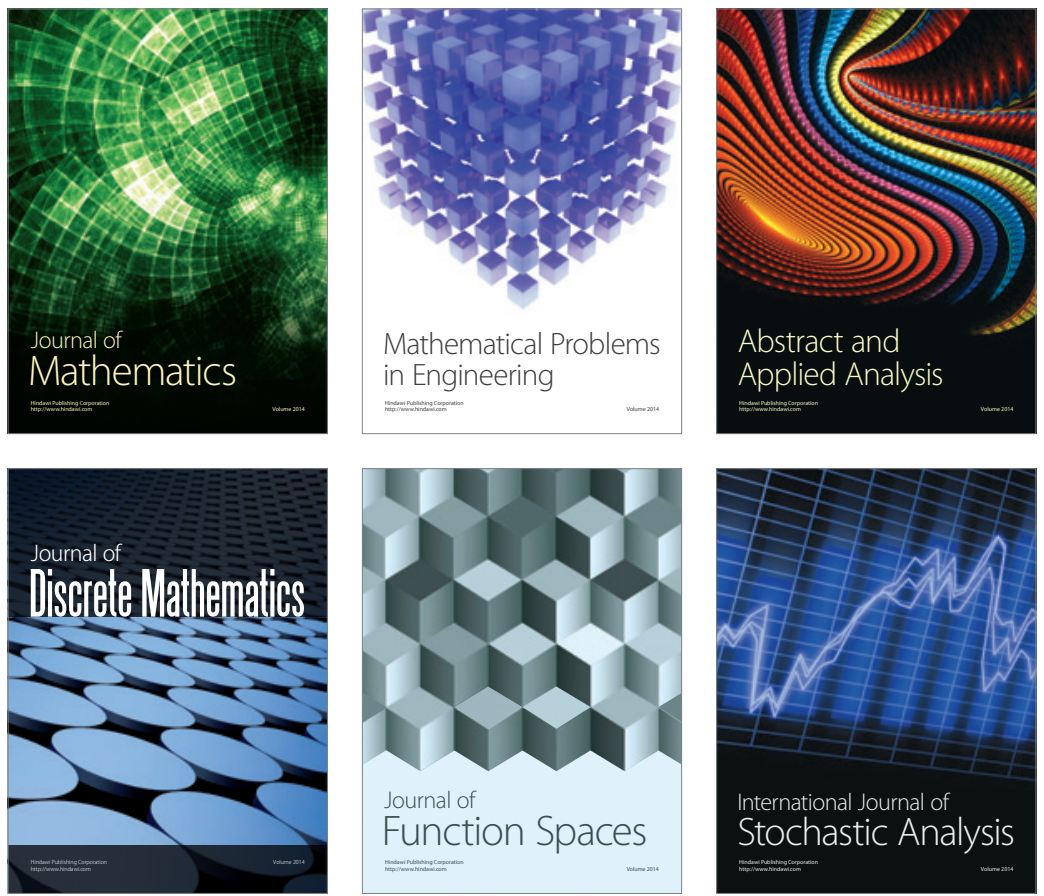

Journal of

Function Spaces

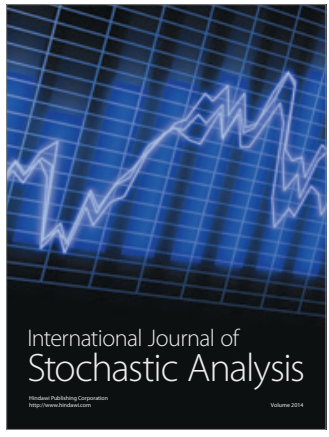

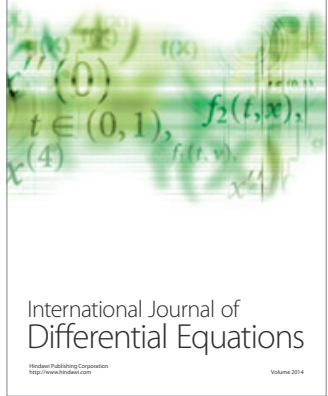
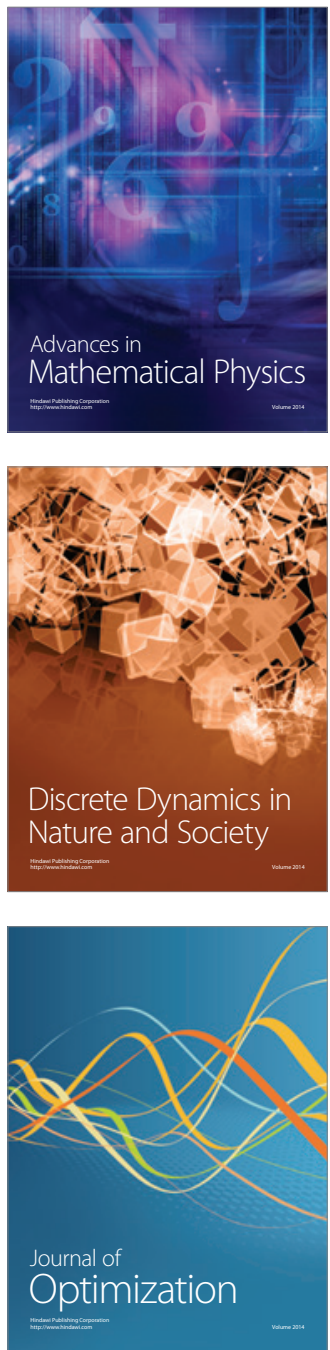